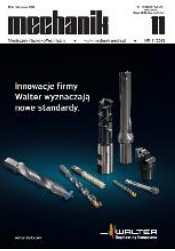

How to cite this article:

Authors: Borys Storch, Łukasz Żurawski

Title of article: "Research on the stages of the wear of the tip cutting edge with a rounding radius based on the mathemat-

ical and geometric model"

Mechanik, No. 11 (2019)

DOI: https://doi.org/10.17814/mechanik.2019.11.93

\title{
Research on the stages of the wear of the tip cutting edge with a rounding radius based on the mathematical and geometric model
}

\author{
BORYS STORCH \\ LUKASZ ŻURAWSKI *
}

Prof. dr hab. inż. Borys Storch, borys.storch@tu.koszalin.pl, https://orcid.org/0000-0001-8576-5894 - Politechnika Koszalińska, Wydział Mechaniczny, Katedra Inżynierii Systemów Technicznych i Informatycznych, Zespół Badawczo-Dydaktyczny Monitorowania Procesów Technologicznych, Koszalin, Polska

Dr inż. Łukasz Żurawski, lukasz.zurawski@tu.koszalin.pl, https://orcid.org/0000-0002-1158-1811 - Politechnika Koszalińska, Wydział Mechaniczny, Katedra Inżynierii Systemów Technicznych i Informatycznych, Zespół Badawczo-Dydaktyczny Monitorowania Procesów Technologicznych, Koszalin, Polska

In modern multiuse cutting tools with exchange plate (e.g. with superfinishing edge or Wiper), the cutting edge is made without documenting the basis for optimizing its dimensions. The article presents a generalized edge wear model surrounded by a rounded tip. The proposed solution allows such a modification of edge corner - by determining the conditions of its work - to adapt the tool to stabilize the process of shaping the machined surface.

KEYWORDS: cutting edge, edge wear model

\section{Introduction}

With cutting time on active cutting edge flank appear wear marks [1, 2], and their picture depends on geometric shape of radius corner.

The most general case of turning cutting edge in the shape of circle segment was considered. The observed wear marks shown in fig. 1 . Three zones have been marked on it with different creation mechanics and different marks image. Typically, wear is concentrated on flank face, and on rake face there is no trace grooved mark. In cut layer under cutting edge rounding there is deformed material layer, the depth of which was up to approx. $0,2 \mathrm{~mm}$ (this area is shown on figure as reinforced layer, and its borders was contoured with the dotted line). With wear increasing in area I appear a characteristic point, where cutting edge crosses deformed layer. Its position determines cutting depth. Around this point appears concentrated wear mark, which width is related to reinforced layer depth. Increased temperature and access of oxygen from free side of cutting edge intensify wear process, what is revealed by long, local wear mark.

In area II wear mark has the shape of rectangular bar, which increase its width over the course of cutting time. In area III wear image is a consequence of highly complex mechanisms. Layer thickness in the cutting zone changes so that $h<h_{\min }$, especially if feed is small, i.e. $f<0,2 \mathrm{~mm} / \mathrm{rev}[3,4]$. The introduction sorted values of cutting depth form $h_{\min 0}$ to $h_{\min 1}$ and angles $\Psi_{\text {kryt }}$ between 67,50 and 77,50 allows for determination of probable cutting depth values [5]. Mechanics of tip corner radius geometry changes was evaluated for those geometric conditions. 


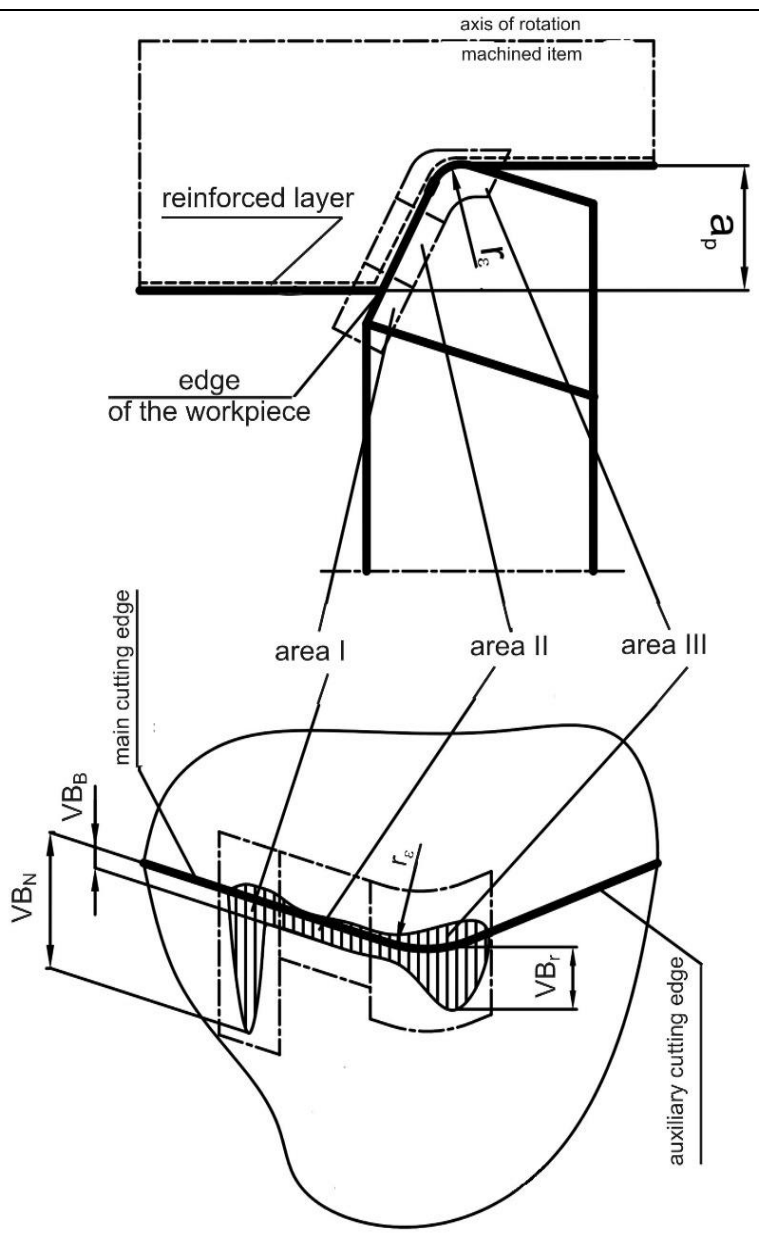

Fig. 1. Wear marks on the tool's working surfaces

\section{Analytical model of cutting edge wear}

The following geometric initial conditions have been used to build the analytical wear model:

- cutting edge has corner radius $r_{\varepsilon}$,

- flank faces are described by $\alpha_{\mathrm{p}}$ and $\alpha_{\mathrm{f}}$ angles,

- rake face is described by $\gamma_{\mathrm{f}}$ angle.

In addition, it has been assumed that due to wear, the cutting edge shall be reduced by the value of $K E$.

\section{Geometric model of tip cutting edge and workpiece}

In the general case, it can be assumed that corner radius is a cylindrical surface segment with radius $r_{\varepsilon}$. The reason for this is that in the tool system, the radius $r_{\varepsilon}$ is formed in a plane parallel to the base plane.

By major and minor contact surface grinding, cylinder circumscribed by this corner is turned in plane $P_{\mathrm{f}}$ through $\alpha_{\mathrm{f}}$ angle and in plane $P_{\mathrm{p}}$ through $\alpha_{\mathrm{p}}$ angle.

\section{General case of the system}

During turning, workpiece is the surface of a cylinder with radius equal to half turning diameter $R=D / 2$. In relation to this cylinder in the coordinate system $X Y Z$, cylinder circumscribed by this corner $r_{\varepsilon}$ was spatially oriented. The axes of the coordinate system passing in such a way that correspond to symmetry axis of applied cylinders (fig. 2a).

On rake face for $\gamma_{\mathrm{f}}>0$ was written circle, which centre lies in point marked $S\left(S_{\mathrm{x}}, S_{\mathrm{y}}, S_{\mathrm{z}}\right)$ (fig. 2b). Through this point also passes the axis of cylinder circumscribed by the corner tip. Distance between cylinders axes, taking into account wear value and tool rake angle impact, is:

$$
S_{\mathrm{y}}=R+r_{\varepsilon}-\Delta
$$


In the equation (1) besides cylinders radii sum $\left(R\right.$ and $\left.r_{\varepsilon}\right)$ there is a value marked as $\Delta$, as the sum of forced by wear, radial sliding $K E$ and caused by tool rake angle $\gamma_{\mathrm{f}}$ correction $Y_{\mathrm{s}}$ (fig. 2a). The requested value $Y=Y_{\mathrm{s}}$, that must be reduced is e to:

$$
Y_{\mathrm{S}}=R-\sqrt{R^{2}-r_{\varepsilon}^{2} \tan ^{2} \gamma_{\mathrm{f}}}
$$

In a plane $X O Z$ cylinder written at cutting edge tip is turned through $\alpha_{\mathrm{f}}$ angle, and therefore also this cylinder generating line should intersect axis $Z$ at this angle. Similarly, in a place $Y O Z$ cylinder generating line is turned through $\alpha_{\mathrm{p}}$ angle. The equation of straight line passing through two points - $M$ and $M^{\prime}$ - which is equation of cylinder generating line, can be derived from:

$$
\frac{X_{0}-X}{0-Z}=\tan \alpha_{\mathrm{f}}
$$

After equation (3) transformation obtains:

$$
Z=\frac{X-X_{0}}{\tan \alpha_{\mathrm{f}}}
$$

Corresponding relation in plane $\mathrm{YOZ}$ is:

$$
\frac{Y_{0}-Y}{0-Z}=\tan \alpha_{\mathrm{p}}
$$

The equation of straight line passing through points $M$ i $M^{\prime}$ and turned through $\alpha \mathrm{f}$ and $\alpha_{\mathrm{p}}$ angles we can write the following form:

$$
Z=\frac{X-X_{0}}{\tan \alpha_{\mathrm{f}}}=\frac{Y_{0}-Y}{\tan \alpha_{\mathrm{p}}}
$$

a)

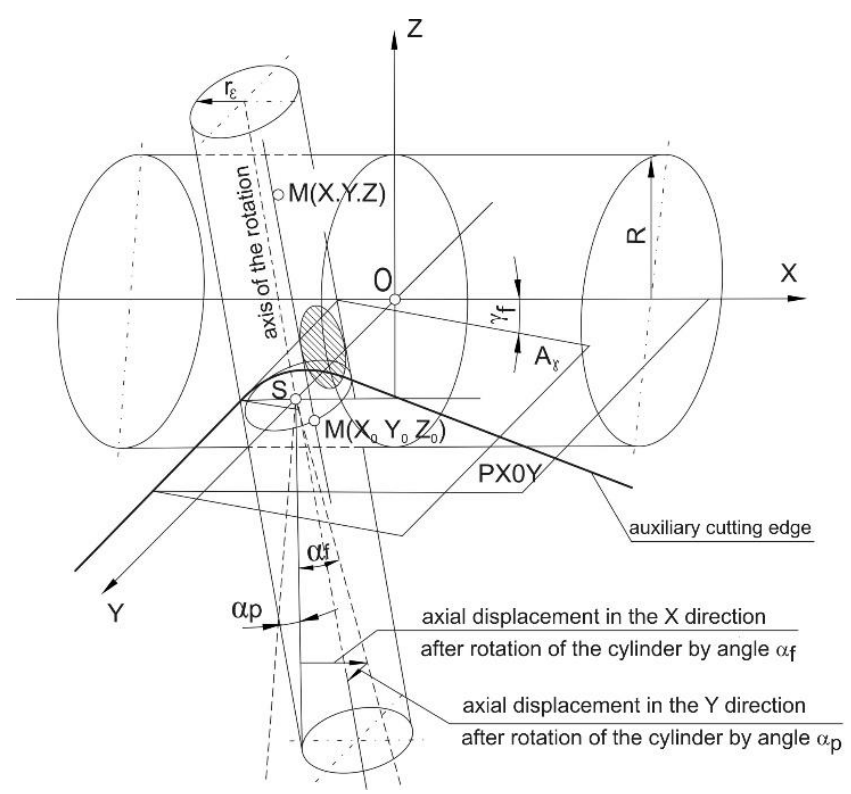

b)

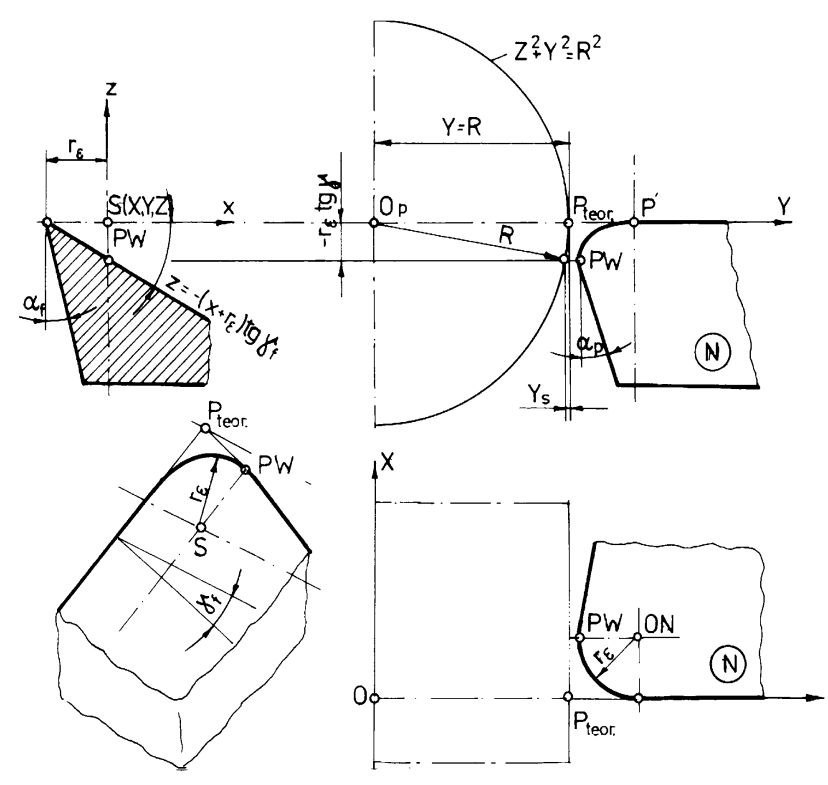

Fig. 2. Cutting part-workpiece geometrical system in an assumed coordinate system (a), and the location of characteristic points on the corner of the cutting edge relative to the workpiece axis (b) 
When each point on generating line is also part of cylinder plane in an assumed cutting part-workpiece system (fig. 2a), and cylinder equation describing a workpiece treated surface take the form:

$$
\left\{\begin{array}{c}
Z^{2}+Y^{2}=R^{2} \\
\left(X+Z \tan \alpha_{\mathrm{f}}\right)^{2}+\left(Y+Z \tan \alpha_{\mathrm{p}}-R-r_{\varepsilon}+K E+Y_{\mathrm{s}}\right)=r_{\varepsilon}^{2}
\end{array}\right.
$$

then the solution is closed spatial curve, which is cutting edge of overlapping cylinders.

\section{Simplified cutting part-workpiece system}

If the $r_{\varepsilon}$ to $R$ ratio is small, it may be assumed that cylinder written at radius tip is cut by $P Y$ plane parallel to the $P X O Z$ plane. $P Y$ plane was placed in the distance of $Y=R$ from the origin of the coordinates. Through corner radius, adjusted before wear at a distance $Y=R$ to workpiece, it's possible - as before - lead cylindrical surface turned through $\alpha_{\mathrm{f}}$ and $\alpha_{\mathrm{p}}$ angles (fig. $2 a$ ). The equation for cylindrical surface is:

$$
\left(X+Z \tan \alpha_{\mathrm{f}}\right)^{2}+\left(Y+Z \tan \alpha_{\mathrm{p}}-R-r_{\varepsilon}+K E+Y_{\mathrm{s}}\right)^{2}=r_{\varepsilon}^{2}
$$

The obtained curve (8) is the equation for real ellipse.

After necessary, auxiliary data calculation and its substituting in the formula (8) characteristic points describing ellipse segment can be determined.

\section{Results of the tool contour wear tests for accepted model}

Side tool contour wear have been tested on turning machine tool TUR50. Steel 55 was machined by highspeed steel tool SW7M. Machined shaft have a diameter $D=100 \mathrm{~mm}$. For the adopted wear value $V B r \approx 0,4 \mathrm{~mm}$ the coordinates of ellipse characteristic points $\left(K E, Y_{\mathrm{s}}, X_{1}, X_{2}, Z_{4}\right)$ was calculated.

In this way, theoretical dimensions of wear mark on minor flank face were determined. Through designated points is drawn ellipse section.

Field limited by ellipse segment determine the area, in which with established machining parameters and tool geometry should be placed increasing real cutting edge wear marks. During cutting test were registered (in 10-minutes intervals) wear marks and they were compared with the theoretical drawing. In this way a wear marks growth record was created. Concluding from the fig. 4 all wear marks growth marks are placed in the theoretical designated area.

Cutting edge wear on the corner radius causes a parallel wear to the machined surface, arising continuously. At the same time the layer is removed and wear surface shaping is changed from the preceding phase.

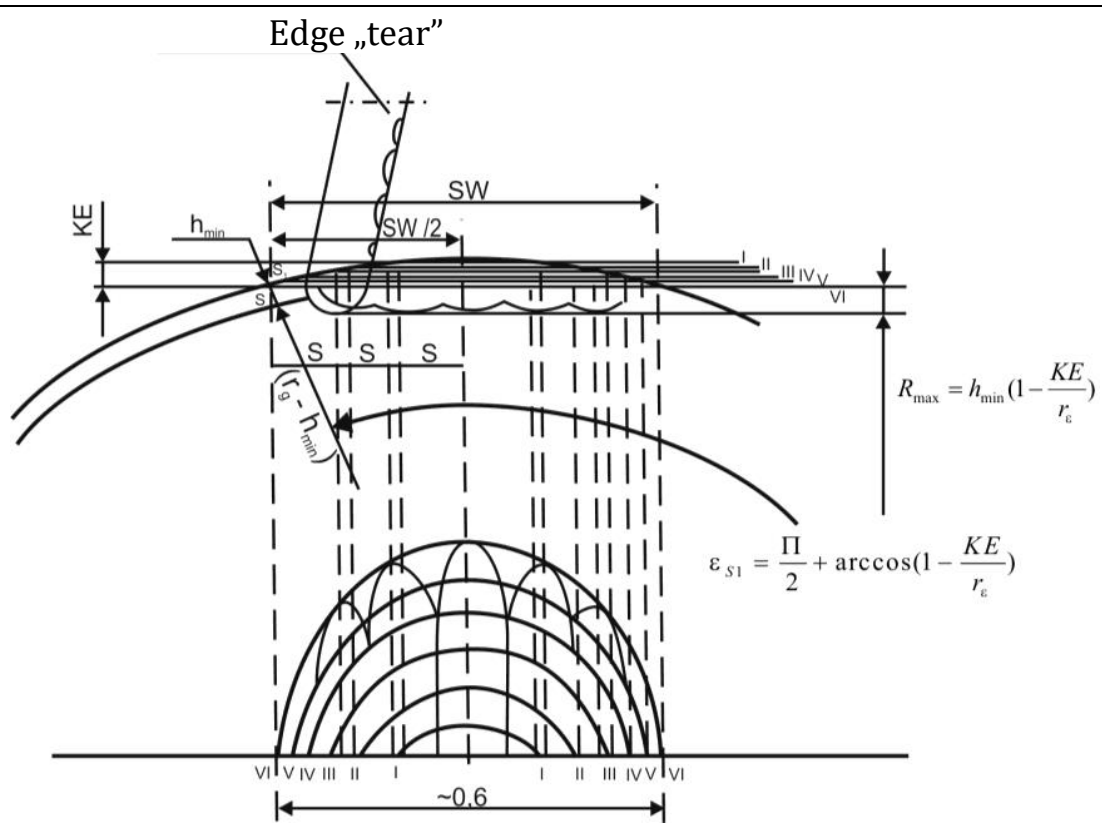

Fig. 3. Model of the formation of concentrated abrasions on the trace of wear of the corner 


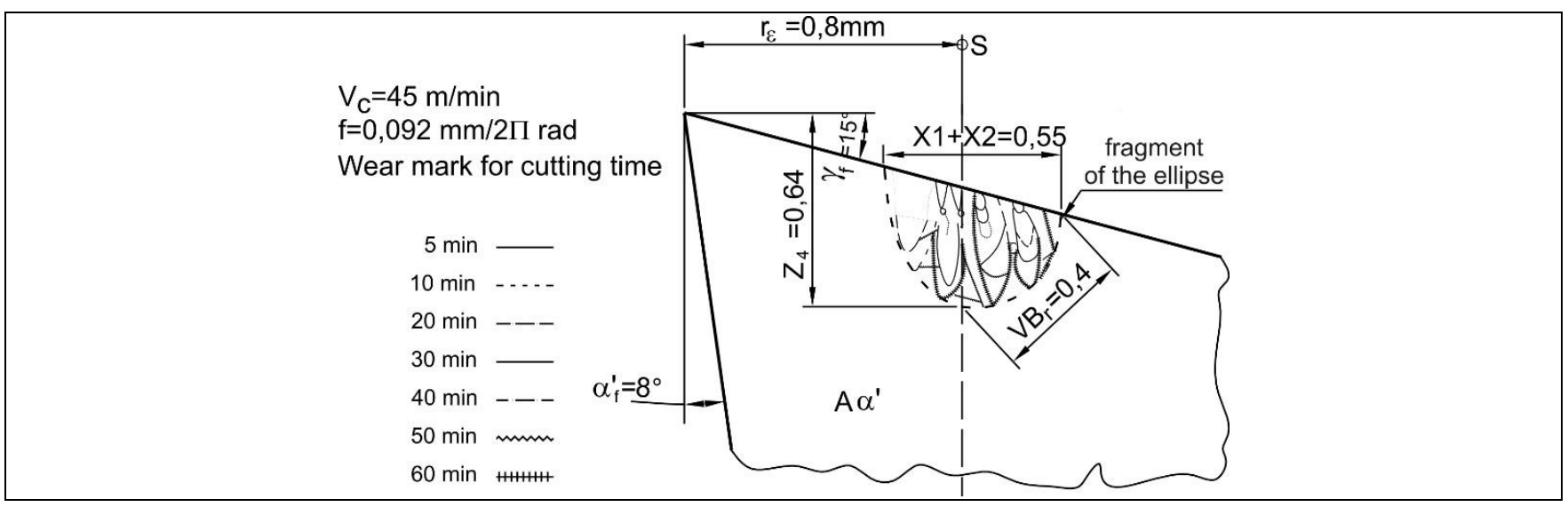

Fig. 4. Auxiliary diagram for calculating the width of the trace of wear on the transition flank

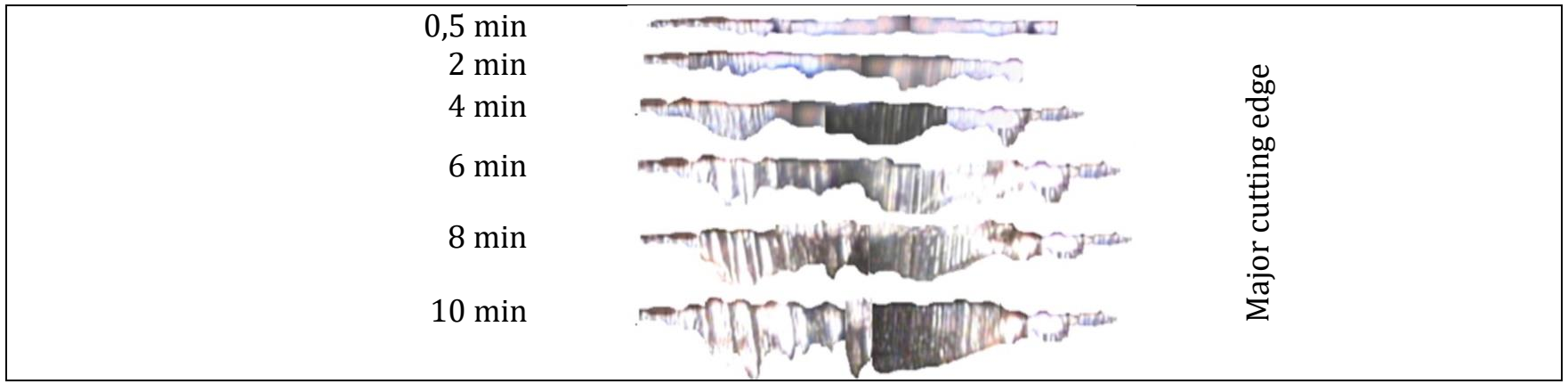

Fig. 5. Digital images of cutting edge wear marks on the edge radius of the cutting edge $r_{\varepsilon}$

\section{Conclusions}

Wear phase after any time increment $\Delta t$ is characterized by the fact that wear zones on ellipse segment from the preceding phase are reducing, and at the same time on the worn surface outlines the new relief with maximum dimension.

Next workpiece rotations leas to contact the "tear" edge with worn surface in specific points, at intervals equal to feed. At the same time, point $S_{1}$ is moving away from the centre line of corner in further wear phases. When the $S W$ distance from centre line of corner is equal to half of feed $\mathrm{f}$, then with a constant workpiece rotation, there is repeated contact the machined surface with wear mark. Point $S_{1}$ is moving towards feed continuously and on $S W$ length surface worn. Contact with reinforced edge take place with the interval equal to feed $f$. With increasing $S W$ surface worn, points of contact on consecutive worn sections equal to feed, move to the left until worn width will increase by value equal to feed. After the time necessary for increased $S W$ width by $f$ repeat cyclical erasure of mark reinforced "tear" with the width equal to feed. Both extreme sections (first from left and last from right) are "redrawn" by the tear edge only once. Those which are situated closer to cutting edge centerline, "has been redrawn" several times.

Movement of "shearing" edge is the continuous passing result of starting point $S_{1}$, related to cross-section, where thickness of cut is $h=h_{\min }$. Please note that cutting edge roundness $r_{\mathrm{n}}$ changes, especially it may increase due to wear developing.

The increase of its value will result in a corresponding increase in value $h_{\min }$.

\section{REFERENCES}

[1] Brammertz P.H. "Die Enstehung der Oberflächenerauheit beim Feindrehen". Industrie Anzeiger. 2 (1961).

[2] Gieszen C.A. "Bas seitliche Verguetschen des Werkstoffes auf den Oberfläehen fein-gedrehter Werkstücke". Fertigung. 5 (1971).

[3] Storch B., Zawada-Tomkiewicz A. "Distribution of unit forces on the tool edge rounding in the case of finishing turning". International Journal of Advanced Manufacturing Technology. 60, 5-8 (2012): 453-461.

[4] Storch B., Zawada-Tomkiewicz A. "Distribution of unit forces on the tool nose rounding in the case of constrained turning". International Journal of Machine Tools \& Manufacture. 57 (2012): 1-9.

[5] Storch B., Zawada-Tomkiewicz A., Żurawski Ł. "Minimal thickness of cut layer in the vicinity of the cutting edge rounding". Mechanik. 10 (2018). 